\title{
Estudo sobre a ocorrência de micronúcleos e alterações nucleares em indivíduos com a Doença de Alzheimer
}

\author{
Study on the occurrence of micronuclei and nuclear abnormalities in individuals with Alzheimer's Disease \\ Flora Bittencourt Lima ${ }^{1}$, Joana América Santos de Oliveira², Layla Damasceno do Espírito Santo³, Lília \\ Maria de Azevedo Moreira ${ }^{4}$ \\ ${ }^{1}$ Mestranda em Ecologia e Conservação da Biodiversidade/UESC; ${ }^{2}$ Doutoramento em Saúde Coletiva/UFBA; \\ ${ }^{3}$ Mestranda em Genética e Biodiversidade/UFBA; ${ }^{4}$ Doutoramento em Genética/USP.
}

\begin{abstract}
Resumo
A doença de Alzheimer (DA) é uma doença neurodegenerativa progressiva, de etiologia complexa, caracterizada clinicamente pela perda de memória e de outras funções cognitivas. Avanços na genética molecular têm indicado a existência de genes que conferem susceptibilidade, sendo o fator genético considerado como preponderante na etiopatogenia da DA. O teste de micronúcleos pode fornecer evidências de danos genotóxicos, que podem estar associadas à manifestação da doença de Alzheimer. Realizou-se esta investigação com o objetivo de verificar a predisposição à formação de micronúcleos e alterações nucleares em indivíduos com DA, tendo em vista contribuir para o conhecimento deste mal, considerado a principal causa de demência entre idosos. Para isto foram amostrados dez indivíduos afetados pela DA comparados a controles do mesmo sexo e faixa etária, e não portadores da doença. $O$ teste de micronúcleo e alterações nucleares foi realizado em células esfoliadas da mucosa oral, com análise de 3000 células por indivíduo. Os dados foram tabulados e submetidos à análise estatística com a utilização do programa Graphpad. Foram observados micronúcleos em taxas não significativas e numero elevado de células em cariólise e cariorréxis, alterações nucleares associadas a fenômenos apoptóticos. A frequência alta destas alterações está de acordo com um epitélio envelhecido e pode ser um indicativo no estudo citopatológico da doença de Alzheimer.

Palavras-chave: Testes para Micronúcleos. Micronúcleos com defeito cromossômico. Doença de Alzheimer.

Abstract

Alzheimer's disease $(A D)$ is a progressive neurodegenerative disease with complex etiology, clinically characterized by memory loss and other cognitive functions. Advances in molecular genetics have indicated the existence of genes that confer susceptibility, and the genetic factor is considered dominant in the AD pathogenesis. The micronucleus test may provide evidence of genotoxic damage, which may be attached for expression of Alzheimer's disease. We conducted this research with the aim of verifying the predisposition to the formation of micronuclei and nuclear abnormalities in individuals with $A D$ in order to contribute to the knowledge of evil, considered the leading cause of dementia among the elderly. For this was sampled ten individuals affected by DA compared to controls of the same sex and age, not with the disease. The micronucleus test and nuclear changes was performed in cells exfoliated from the oral mucosa, with analysis of 3000 cells per individual. Data were tabulated and statistically analyzed using the program Graphpad. Micronuclei were observed at rates not statistically significant and high number of cells in cariorréxis and karyolysis, nuclear changes associated with apoptotic phenomena. The high frequency of these changes is in accordance with an epithelium, and may be aged in cytopathological indicative of Alzheimer's disease.
\end{abstract}

Keywords: Micronucleus Tests. Micronuclei, Chromosome-Defective. Alzheimer Disease.

\section{INTRODUÇÃO}

A doença de Alzheimer (DA), descrita inicialmente pelo neuropatologista alemão Alois Alzheimer em 1907 (ALZHEIMER, 1907), é uma doença neurodegenerativa progressiva do envelhecimento, de etiologia complexa, caracterizada clinicamente pela perda de memória e outras funções cognitivas (TRIPPI et al, 2001). O risco da doença apresenta aumento exponencial com a idade, dobrando a cada cinco anos, a partir da idade de 65 anos (ZABAR, 2006).

Atualmente exames de neuroimagem associados a avaliações cognitivas são utilizados para o

Recebido em 26/01/2012; revisado em 11/03/2012.

Correspondência / Correspondence: Lilia Maria de Azevedo Moreira. Laboratório de Genética Humana e Mutagênese (LGHM) / Programa Genética \& Sociedade- Departamento de Biologia - Instituto de Biologia-UFBA. Av. Barão de Geremoabo, 147, sala 10-Campus de Ondina.40170-290 Salvador-Bahia. e-mail: lazevedo@ufba.br diagnóstico clínico, embora o diagnóstico definitivo da DA só possa ser feito mediante análise histopatológica do tecido cerebral post morten, por achados patológicos típicos. O primeiro destes é a deposição excessiva da proteína beta-amilóide no cérebro, com formação de placas senis, de distribuição difusa no córtex cerebral que acarretam a perda progressiva de sinapses em extensas áreas e pode explicar o sinal clínico mais precoce da doença: a perda da memória recente. Outros achados patológicos relevantes são os emaranhados neurofibrilares que surgem no interior da célula, formados pela proteína tau associada à microtúbulos, cujo número e distribuição têm relação direta com a gravidade da demência (ZABAR, 2006).

Gallucci e colaboradores (2005) destacam a importância dos critérios do NINCDS - ADRDA (National 
Institute for Communicative Disorders and Stroke Alzheimer's Disease and Related Disorders Association), para o diagnóstico da doença que incluem a demência estabelecida por exame clínico e documentada pelo Mini-Exame do Estado Mental (MEEM), escala de demência Blessed, ou avaliação similar, déficits em duas ou mais áreas da cognição, piora progressiva da memória e outras funções cognitivas. Estudos comparativos da média alcançada no escore do MEEM em pacientes com a DA com a formação de placas senis, caracterizam o teste como importante instrumento de triagem (NITRINI et al, 2005). Observa-se o declínio do escore no MEEM quando se instalam os sinais extrapiramidais e o aparecimento de tais sinais têm consequências diretas na progressão, tanto cognitiva quanto funcional, pois nas atividades da vida diária a detecção desses sinais é associada a uma persistente mudança nos escores em cada avaliação feita (FORLENZA; CARAMELLI, 2000).

Entre os possíveis fatores ambientais, o baixo nível educacional e o traumatismo craniano são frequentemente associados à $D A$, embora com resultados ainda controversos (FREITAS et al, 2002). Uma das hipóteses para explicar a associação entre demência e baixa escolaridade é a menor capacidade de compensação para qualquer déficit cognitivo (SMITH, 1999). Outros fatores como a toxicidade a agentes infecciosos, ao alumínio, a radicais livres de oxigênio, a aminoácidos neurotóxicos e a ocorrência de danos em microtúbulos e proteínas associadas, também são relacionados à etiologia da Doença de Alzheimer (SMITH, 1999).

Avanços da genética molecular têm indicado a existência de genes que conferem susceptibilidade e o fator genético tem sido considerado como preponderante na etiopatogenia da DA. A história familiar positiva de demência é também considerada como um importante fator de risco (SMITH, 1999). O risco de desenvolver a DA é 3,5 vezes maior em indivíduos que têm pelo menos um parente em primeiro grau com demência (FITZGERALD; MCEWAN, 1977).

Os fatores de risco para a doença de Alzheimer, já comprovados por estudos epidemiológicos são: idade, história familiar positiva e síndrome de Down. Com relação a esta síndrome, foi demonstrado que muitos portadores que atingem a idade de 40 anos apresentam as alterações neuropatológicas típicas da DA, possivelmente por apresentarem uma cópia extra do gene da APP, codificada no cromossomo 21 (FRANCHESCHI et al, 1991).

Considerando-se a associação de marcadores citogenéticos com a doença de Alzheimer, faz-se necessário investigações nesta área, com metodologias alternativas que possam contribuir para o conhecimento de fatores etiológicos desta doença neurodegenerativa, que apresenta prevalência crescente em consequência ao aumento do envelhecimento da população.

Migliori e colaboradores (1997) referem níveis significantes de aneuploidias e alto percentual de divisão prematura do centrômero em casos esporádicos da doença de Alzheimer. Trippi e colaboradores (2001) verificaram frequência de $\mathrm{MN}$ significantemente elevada em células de casos esporádicos e familiais de DA, quando comparados a grupo controle. $O$ teste de micronúcleos pode fornecer evidências de danos genotóxicos, que podem estar associadas à manifestação da doença de Alzheimer. Além de micronúcleos, podem também ser observadas outras alterações nucleares, como cariorréxis e picnose (associadas ao processo de morte celular) assim como a cariólise, relacionada à necrose (TOLBERT et al, 1992).

Considerando que os estudos que avaliam a ocorrência de danos citogenéticos na doença de Alzheimer ainda são escassos, foi realizada esta investigação, com o objetivo de verificar a ocorrência de micronúcleos e outras alterações nucleares em portadores da doença.

\section{METODOLOGIA}

A investigação foi realizada com metodologia caso-controle, comparando-se sujeitos que tiveram diagnóstico clínico da doença de Alzheimer em serviço de Geriatria de Salvador-Bahia, de acordo com os critérios do NINCDS - ADRDA, com idosos da mesma faixa etária sem o distúrbio, totalizando 20 participantes, de ambos os sexos e acima de 60 anos de idade.

Todos os participantes e seus responsáveis foram devidamente orientados sobre a pesquisa e solicitados a assinar um termo de consentimento livre esclarecido, de acordo com as normas da Resolução 196/96, do Conselho Nacional de Saúde, onde está declarado o direito de abandono à pesquisa pelo sujeito em qualquer momento, se assim desejar. Também foi respeitado o anonimato de cada participante, assim como os dados individuais coletados. $O$ estudo foi aprovado pelo Comitê de Ética da FAPESB/PIBIC-Bahia.

$O$ estudo foi realizado entre setembro de 2005 a janeiro de 2006, sendo iniciado com entrevista estruturada para registro de antecedentes genéticos, saúde, hábitos de vida e o Mini-Exame do Estado Mental, como forma de avaliar a história e o déficit cognitivo e funcional dos indivíduos.

A análise do micronúcleo foi feita em células de esfregaços da mucosa oral, coletadas por raspagem cuidadosa com espátula de madeira, e espalhadas em lâminas de vidro, de acordo com o protocolo de Tolbert e colaboradores (1992) . De cada indivíduo foram analisadas 3000 células, em microscópio óptico, com objetiva 40X. 
Os dados da análise citogenética foram tabulados e submetidos à análise estatística, utilizando o programa GraphPad, para a aplicação dos testes. A avaliação das diferenças entre os grupos caso e controle foi inicialmente realizada pelo teste KolmogonovSmirnov para testar a normalidade dos dados e posteriormente com o teste de Bartlett para testar a homogeneidade das variâncias. Sendo observado que os dados não possuíam validade para uma análise paramétrica, estes foram transformados, aplicando a equação LOG $(X+1)$ para cada um dos valores obtidos.

Para os valores transformados, aplicou-se o teste de normalidade e de homogeneidade das variâncias, exceto para os dados obtidos com as análises das células binucleadas, aplicando-se para essas células o teste não paramétrico de Welch. 0 resultado da transformação era testado, utilizando o teste $t$ de Student, para amostras independentes, com nível de significância de $5 \%$.

\section{RESULTADOS E DISCUSSÃO}

Para os 10 indivíduos de cada grupo foram analisadas 30.000 células $(10 \times 3.000=30.000$ por grupo amostral, totalizando 60.000 células). Os dados obtidos com a observação ao microscópio e análise estatística do teste de micronúcleo e de anormalidades nucleares são apresentados na Tabela 1.

A comparação entre a frequência de micronúcleos entre os grupos revelou aumento não significativo de $\mathrm{MN}$ nos pacientes com Alzheimer $(p=0,746)$. Estudos acerca do aumento de $M N$ na doença de Alzheimer, referem, entretanto, que a indução do micronúcleo apresentou-se parcialmente reduzida ou ausente, de acordo com o tipo de tratamento clínico utilizado pelos pacientes, variável não considerada no presente estudo ( MIGLIORI, 1997).

A análise das alterações nucleares não mostrou diferenças significativas na ocorrência de cariólise $(p=0,853)$ e de células binucleadas $(p=0,157)$. Entretanto, quando foram comparados os valores obtidos para as células com cariorréxis nos 2 grupos, observou-se diferença muito significativa $(p=0,0021)$, sendo maior nos sujeitos. Não obstante o desvio padrão elevado, o grande número de células analisadas em cada indivíduo permite que o achado de aumento de alterações nucleares na DA seja considerado um resultado relevante deste estudo. Cariorréxis e cariólise têm sido apontadas como associadas a fenômenos apoptóticos e também indicativas de citotoxicidade e genotoxicidade, alterações associadas ao processo do envelhecimento.

Ao correlacionar a ocorrência de alterações nucleares com o resultado obtido no teste MEEM para os indivíduos com o diagnóstico da doença de Alzheimer, foi observada maior frequência dessas, em pacientes com menor escore teste, como pode ser observado no Gráfico 1.

$\mathrm{Na}$ Doença de Alzheimer ou em outras doenças mentais, testes como o MEEM são levados em conta durante todo o processo de investigação da enfermidade como forma de avaliar a progressão da mesma. Considerando-se as observações individuais, verificouse uma relação entre o estado mental de cada paciente, expresso por escore do MEEM, com a quantidade de micronúcleos ou alterações nucleares. Por exemplo, o paciente $n^{\circ} 5$, o que alcançou maior escore ( 26 pontos), não evidenciou micronúcleos em suas 3.000 células

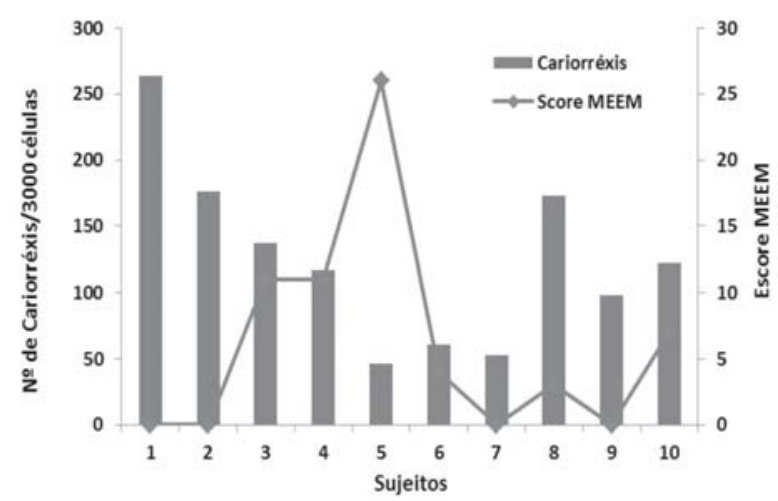

Gráfico 1. Relação entre escore MEEM e a ocorrência de cariorréxis nos sujeitos do estudo.

Tabela 1. Dados de média e desvio padrão referentes ao número de alterações nucleares (micronúcleo, cariorréxis e cariólise) em grupos sujeito e controle.

\begin{tabular}{|c|c|c|c|c|}
\hline & & \multicolumn{3}{|c|}{ Alteração nuclear } \\
\hline & & Micronúcleo & Cariorréxis & Cariólise \\
\hline \multirow{2}{*}{ Média } & Grupo Sujeito & 2,3 & 124,7 & 431,3 \\
\hline & Grupo Controle & 2,7 & 51,6 & 449,3 \\
\hline \multirow{2}{*}{ Desvio Padrão } & Grupo Sujeito & 3,65 & 67,24 & 336,4 \\
\hline & Grupo Controle & 3,3 & 19,9 & 273,63 \\
\hline \multicolumn{2}{|c|}{ Valor de $\mathrm{P}^{*}$} & 0,7465 & 0,0021 & 0,8531 \\
\hline
\end{tabular}

* Teste $t$ de Student para amostras independentes - Transformação LOG $(X+1)$. Nível de significância de 5\%. 
observadas. No mesmo sujeito, observou-se também que a quantidade de cariorréxis não foi elevada, havendo ocorrência expressiva apenas no número de células binucleadas, as quais poderiam ter sido causadas por outras enfermidades ou maus hábitos cotidianos.

Em contraste, no paciente $n^{\circ} 6$, com escore do MEEM $=4$ pontos, observou-se 12 micronúcleos no mesmo total de células estudadas, nenhuma célula binucleada e maior quantidade de cariorréxis. Observação semelhante foi feita no paciente $n^{\circ} 1$, escore 0 , com ocorrência elevada de células em cariorréxis (264), 03 células com micronúcleos e 04 células binucleadas.

\section{CONCLUSÕES}

Embora a observação destes biomarcadores, em frequência elevada permita sugerir que estes podem funcionar como indicadores de injúria celular recomenda-se a realização de pesquisas adicionais com maior número de idosos, para a validação do teste.

Os resultados obtidos no presente estudo apontam para a importância de novas abordagens no diagnóstico da doença de Alzheimer e valorizam também as avaliações de aspectos cognitivos na detecção de doenças neurodegenerativas.

\section{REFERÊNCIAS}

ALZHEIMER, A. Über eine eigenartige Hirnrinde. Allgemeine Zeitschrifte Psychiatrie, Berlin, v.64, p. 146-148, 1907.
FITZGERALD, Peter H.; MCEWAN, Christiane M. Total aneuploidy and age-related sex chromosome aneuploidy in cultural lymphocytes of normal man and women. Human. Genetics., Englewood Cliffs, Nova Jersey, v. 39, n. 3, p. $329-337,1977$.

FORLENZA, O.V.; CARAMELLI,P. Neuropsiquiatria Geriátrica. São Paulo: Editora Atheneu, 2000. 609 p.

FRANCHESCHI,C. et al. Studies in centenarians (successful aging) and patients with Down's syndrome (accelerated aging). Ann. N. Y. Acad. sci., New York, v.663, p. 428-440, 1992.

FREITAS, E.V. et al. Capitulo. Tratado de Geriatria e Gerontologia. Rio de Janeiro: Editora Guanabara Koogan, 2011. 1750 p.

GALLUCCI, J.N.; TAMELINI, M.G.; FORLENZA, O.V. Diagnóstico diferencial das demências. Rev. Psiquiatr. Clín., São Paulo, v. 32, n.3, p. 119-130, 2005.

MIGLIORI, L. Spontaneous and induced aneuploidy in peripheral blood lymphocytes of patients with Alzheimer disease. Hum. Genet., Berlin, v. 101, n. 3, p.299-305, dec. 1997.

NITRINI, R. et al. Diagnóstico da Doença de Alzheimer- Avaliação cognitiva e funcional. Arq. Neuro-Psiquiatr., São Paulo, v. 63, n.3, p. 720-727, sep. 2005 .

SMITH, M. A. C. Doença de Alzheimer. Rev. Bras. Psiquiatr., São Paulo, v. 21, n. 2, p. 31-32, oct. 1999.

TOLBERT, PE; SHY, CM; ALLEN, JW. Micronuclei and other nuclear anomalies in buccal smears: methods development. Mutat. Res., Amsterdam, v. 271, n. 1, p. 69-77, Feb. 1992.

TRIPPI, F. et al. Spontaneous and induced chromosome damage in somatic cells of sporadic and familial Alzheimer's disease patients. Mutagenesis., Oxford, v. 16, n. 4, p. 323-27, Jul 2001.

ZABAR,Y. Doença de Alzheimer. In: JONES JR, H Royden. Neurologia de Netter,. Porto Alegre: Artmed Editora. 2006. cap.32. p.355-374. 